\title{
Significance of Monoclonal PCSK9-Antibodies - New Approaches to the Therapy of Hypercholesterolemia
}

\author{
Claas L. Neumann ${ }^{\mathrm{a}}$ Elke Schettler ${ }^{\mathrm{a}}$ Volker J.J. Schettler ${ }^{\mathrm{b}}$ \\ a BRAVE - Benefit for Research on Arterial Hypertension, Dyslipidemia and Vascular Risk and Education e.V., \\ ${ }^{b}$ Nephrologisches Zentrum Göttingen GbR, Göttingen, Germany
}

\section{Key Words}

PCSK9 inhibition · LDL-cholesterol · Lipoprotein(a) ·

Lipoprotein apheresis · Therapy algorithm

\begin{abstract}
Increased concentrations of low-density-lipoprotein (LDL)cholesterol (LDL-C) and lipoprotein a (Lp(a)) are scientifically accepted, independent risk factors for the development of atherosclerosis. The complications of atherosclerosis occur early and more frequently. They are strongly linked with lifestyle factors and an increase of LDL-C concentrations in industrialized countries. A new therapeutic approach seems to be the modulation of the proprotein convertase subtilisin/ kexin type 9 (PCSK9), which reduces the number of LDL-receptors at the cell membrane of the liver cells and thus increases the concentration of LDL-C in the blood. Results of current studies show, that in particular, a combination of PCSK9-AB and statins, independent of the dosage of the statins, is suitable to increase a reduction of LDL-C and $L p(a)$. This article gives an overview of the pathophysiology, the current study and research situation as well as the possible different approaches to the therapeutic influence of PCSK9 in the future.

(c) 2016 S. Karger AG, Basel
\end{abstract}

\section{Introduction}

Increased concentrations of low-density-lipoprotein (LDL)-cholesterol (LDL-C) and lipoprotein a (Lp(a)) are scientifically accepted, independent risk factors for the development of atherosclerosis and its complications, such as myocardial infarction, stroke or peripheral arterial disease [1]. With industrialisation, a severe change in physical activity (less movement e.g. in sedentary activities) and nutrition patterns (high-calorie and high-fat diet) is observed in industrialized countries.

Increased inactivity and unbalanced nutrition in part are responsible of causing metabolic syndrome even in the younger population, leading to for example, myocardial infarction, which is no longer a phenomenon of ageing $[2,3]$. Also, the lipid profiles associated with these changes in metabolism are, in absence of diabetes, mostly those of type IIa/IIb Frederickson's hyperlipoproteinaemia or an increase of LDL-C in combination with Lp(a) hyperlipidaemia, respectively. A large number of randomised studies have found that a reduction in LDL-C, especially by statins, is connected to a significant reduction of additional cardiovascular events of the respective patients (secondary prevention) [4]. Statins were also

\section{KARGER}

E-Mail karger@karger.com

www.karger.com/bpu
(C) 2016 S. Karger AG, Basel

0253-5068/16/0414-0270\$39.50/0
Priv. Doz. Dr. med. Volker J.J. Schettler

Nephrologisches Zentrum Göttingen

An der Lutter 24

DE-37075 Göttingen (Germany)

E-Mail v.schettler@nz-goe.de 
shown to prevent cardiovascular events in patients with hyperlipidaemia all together [5]. In these studies, next to statins, other lipid-lowering medication, such as nicotinic acid, was employed.

Evidence of an advantage of a combined application of statins and nicotinic acid in preventing cardiovascular events over statin monotherapy is not compelling [6]. If elevated $\mathrm{Lp}(\mathrm{a})$-concentrations are responsible, therapy options are still very limited. Statins have only a small impact on Lp(a)-levels.

Currently, no medication licensed in Europe is able to effectively reduce $\mathrm{Lp}(\mathrm{a})$-concentrations with a long-lasting impact. The clinical effects of the $\operatorname{Lp}(\mathrm{a})$-reduction achieved by nicotinic acid have been disputed and are connected to major adverse effects [7]. Following negative study outcomes, nicotinic acid was withdrawn from the European markets. Therefore, the only effective therapy available today is chronic lipid apheresis (LA) treatment in weekly intervals. For this extracorporeal method, it was recently shown that the high rate of cardiovascular events can be reduced by at least $78 \%$ under chronic LA treatment $[8,9]$. Broader usage of statin therapy is limited by the occurrence of adverse effects, such as myopathies including rhabdomyolysis or elevated liver function tests, leading in most of the affected cases to cancellation of statin therapy. While a large variety of statins exists, which in part are metabolised very differently (e.g. Cytochrome P450 3A4, glucuronidation), the aforementioned adverse effects cannot be avoided by a change in statin type in all cases [10]. Beyond the outlined options, there exists a clear need for additional forms of lipid-lowering therapy, which is also documented in the current guidelines of the European Society of Cardiology and the European Artherosclerosis Society [11].

The PROVE-IT study showed, for example, that some patients with cardiovascular affection retained a risk of $22.4 \%$ to encounter an event in the following 2 years [12]. Furthermore, for Germany, the analysis of the 2L-registry (adherence of hospital-based cardiologists to lipid guidelines in patients at high risk for cardiovascular events) allows to critically remark that not all patients with established cardiovascular damage receive adequate statin or other lipid-lowering medication. Some of the LDL-C target values set by current guidelines are met in less than $50 \%$ of cases [13]. In light of the cost of the now much differentiated development of new lipid-lowering medications, the capacity of existing substances should be used to its full extent where clinically justifiable.

The anti-sense-oligonucleotide-therapy (mipomersen) acting on the apolipoprotein B100 achieving significant LDL-C and $\mathrm{Lp}(\mathrm{a})$-reduction rates was promising as a new effective medication [14]. Licensing for the European market was, however, declined by the European Medicines Agency (EMA) due to adverse effects. Here, elevated liver function tests and non-alcohol-induced fatty liver development were observed and these conditions led to increased cancellation rates (EMA/177547/2013). The EMA found that the effects of long-term therapy could not be satisfactorily determined by the product developers. Currently, patients exhibiting severe lipometabolic disorder, those remaining at levels of LDL-C $>130 \mathrm{mg} / \mathrm{dl}(3.4 \mathrm{mmol} / \mathrm{l})$ or $\mathrm{Lp}(\mathrm{a})>60 \mathrm{mg} / \mathrm{dl}$ (>120 nmol/l according to WHO-standard SRM B2) despite dietary and medicinal measurements, and those deteriorating from progress of their cardiovascular affection are successfully treated by continuous lipoprotein apheresis, chiefly in weekly intervals [15].

\section{PCSK9 in the LDL-C Metabolism}

Proprotein convertase subtilisin/kexin type 9 (PCSK9) is seemingly an important protein in the LDL$\mathrm{C}$ metabolism. It is, in particular, involved in the regulation of LDL receptor (LDL-R) degradation. The effectivity of exploiting this mode of action of PCSK9 to tackle severe lipometabolic disorder was discovered comparably late. While first reports on mutations in gene sequences of the LDL-R or the apolipoprotein B100 were published in the late 70 s and 80 s of the 20 th century, the work group of Abifadel et al. [16] discovered in 2003, first in 2 French families, a mutation in the gene sequence in PCSK9 related among other things to elevated levels of LDL-C.

To this date, only a few additional PCSK9-mutations are known. The current state can be learnt from http://www. ucl.ac.uk/ldlr. In the follow-up of the findings, numerous experimental investigations on cells and animals were conducted, successfully, elucidating the exact function of PCSK9 with respect to LDL-R (fig. 1). PCSK9 is intracellularly generated, independent of LDL-R and emitted to the cell surface. After PCSK9 has detached from the surface, it binds directly to free LDL-R. If mediated by apolipoprotein $\mathrm{B} 100$ an LDL-C molecule attaches to the receptor, the resulting complex including PCSK9 is internalised (endocytosis). Via transport paths, the endosome fusions with one or more lysosomes in such a way, that not only the constituents of the LDL-C molecule are completely decomposed, but the internalised LDL-R is as well decomposed. In case of a genetically caused elevation of PCSK9, the LDL$\mathrm{R}$ concentration in the membrane is significantly reduced, resulting in an increase in LDL-C in serum [17]. 
Fig. 1. LDL metabolism in the presence of PCSK9. PCSK9 is formed in the hepatocyte and travels to the cell surface to exit into circulation, where it binds to LDL-R on the cell surface. In the presence of PCSK9, the LDL-R pathway is altered: The PCSK9/ LDL-R complex enters the cell via endocytosis. The LDL- $\mathrm{R}$ undergoes lysosomal degradation rather than recycling. As a result, fewer receptors are available on the cell surface to remove LDL-C.

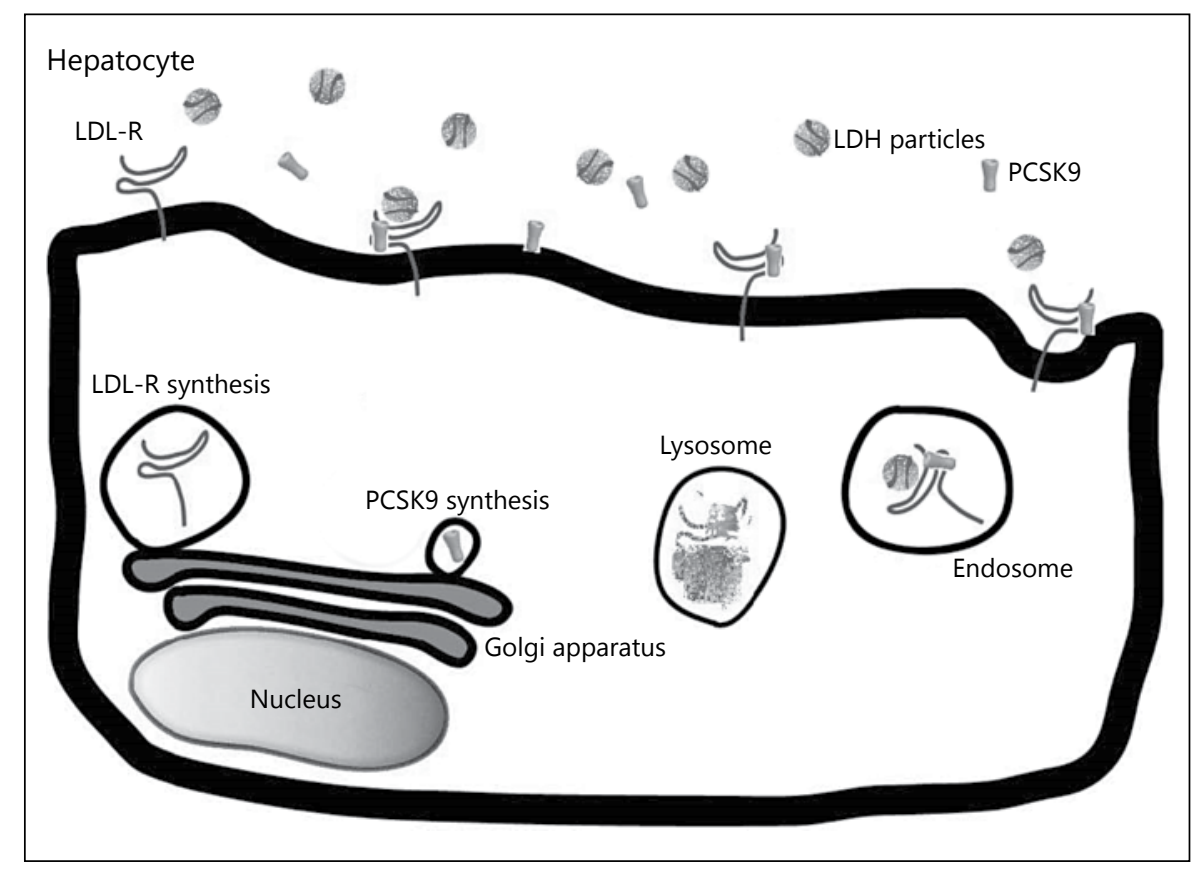

In the process of searching for different mutations of PCSK9 in humans, Cohen et al. [18] found 2 special variations. In these cases, opposed to mutations discovered earlier, where an overexpression of PCSK9 was observed, here PCSK9 was found inactive as a consequence of a socalled nonsense mutation. This refers to the expression of a form of PCSK9 incapable to bind to LDL-R.

These studies furthermore showed for the first time, that the occurrence of PCSK9 without function is indeed connected to an increase in LDL-R and subsequent reduction of S-LDL-R levels by up to $40 \%$ as compared to the known mean value. These variations in PCSK9 are related to low rates of cardiovascular events and have exhibited no obvious negative impact on the human organism [19]. Therefore, the development of therapy measures targeting PCSK9 activity and/or the PCSK9-LDL-R binding mechanism has been initiated (table 1).

This publication focuses on work, trails and their results on the mechanism of monoclonal antibodies (PCSK9-AB) acting on PCSK9. Examples for these have been successfully used in phase-III studies. The principle of action of these substances is a binding to PCSK9 in such a way that subsequent binding to LDL- $\mathrm{R}$ is rendered impossible. As a consequence, LDL-R-LDL-C complexes are internalised in the absence of PCSK9, which results in the degradation of LDL-C only, while the LDL-R is 'recycled' and directly returned to the membrane (fig. 2).

\section{Overview of Study Results}

The monoclonal PCSK9-AB Evolocumab (Amgen) and Alirocumab (Sanofi-Regeneron) are both applied in several phase-III studies, for example, DESCARTES, ODYSSEY, for a long term. Another PCSK9-AB, Bococizumab (Pfizer), is close to finish a first phase-III study SPIRE-LDL [20] (table 1). Existing PCSK9-AB studies show the mechanism described earlier to work very well. Monoclonal antibodies block PCSK9 and induce an increase in the number of LDL-R associated with increased reduction in LDL-C serum concentrations. Following the hypothetical principle of action, it was assumed that the mechanism is particularly effective if LDL-R is retaining its full functionality in the process. In this regard, it is surprising that there are results documenting a reduction in LDL-C by up to $55 \%$ even in patients exhibiting mutations of LDL-R, for example, in patients with hyperlipidaemia of heterozygous or homozygous variety [21]. However, these results were obtained from a small sample with large variance in the LDL-C reduction rate. Larger studies are required to derive reliable results and general recommendations. Furthermore, it is noteworthy that a combination of statins and PCSK9-AB seems particularly effective in LDL-C reduction. Patients receiving therapy by PCSK 9 and statins show an additional reduction in LDL-C by $50-60 \%$ compared to statin mono-therapy. Another interesting fact is that the effect was measured 
Fig. 2. Effect of monoclonal PCSK9-antibodies on the LDL metabolism. When PCSK9 binds to an LDL- $R$, the receptor is destroyed along with the LDL particle. But if PCSK9 does not bind, the receptor can return to the surface of the cell and remove more cholesterol.

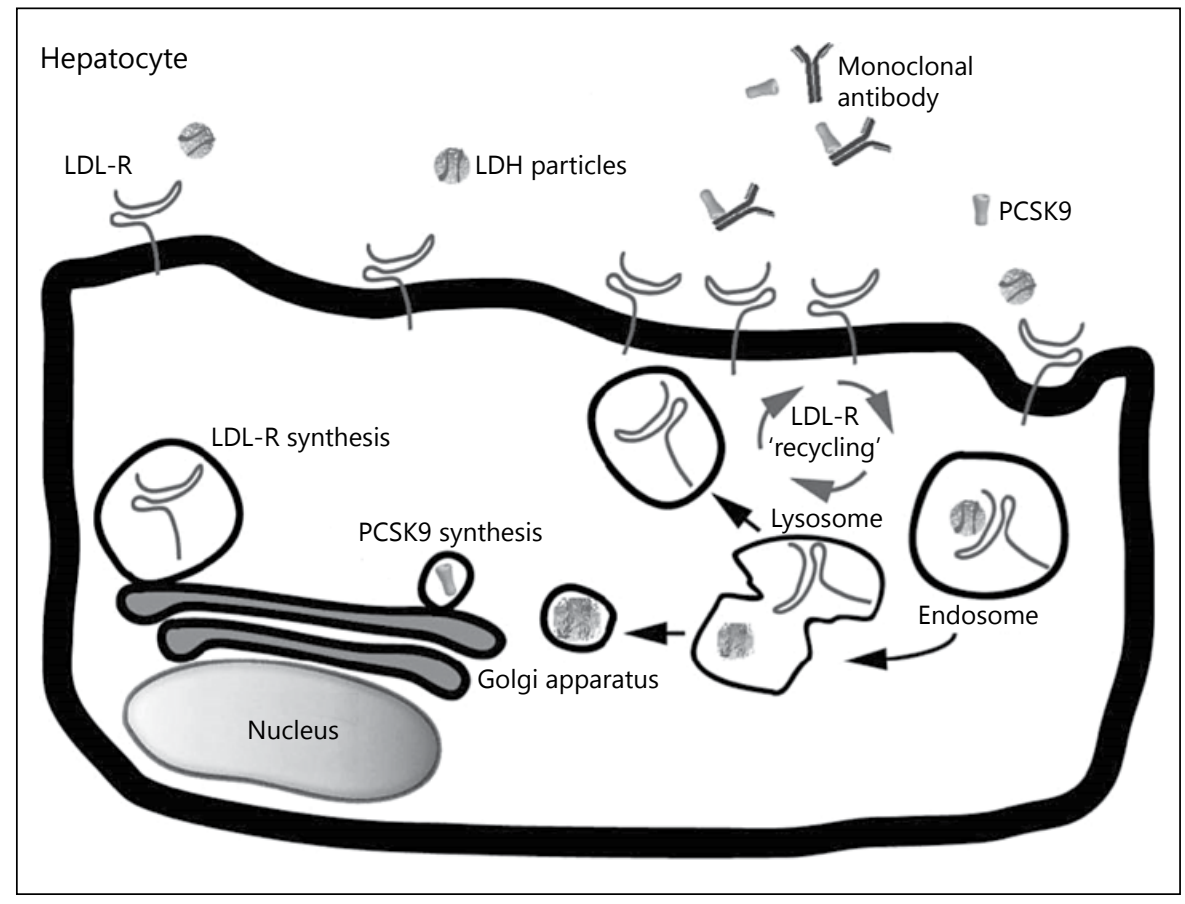

Table 1. Overview of PCSK9-inhibitors and other PCSK9 modulators with pharma companies and type of study (March 2015; numbers in brackets refer to the citations of the particular trials)

\begin{tabular}{|c|c|c|}
\hline Substance & Pharma company/working groups & Type of study \\
\hline \multicolumn{3}{|c|}{ PCSK9-antibodies and modulators (date of publication: March 2015) } \\
\hline Alirocumab (REGN727 and SAR236553) & Sanofi [31] & $\begin{array}{l}14 \text { phase III trials with } 23,000 \\
\text { patients }\end{array}$ \\
\hline Evolocumab (AMG-145 or AMG145) & Amgen $[32-34]$ & $\begin{array}{l}20 \text { phase III trials with } 30,000 \\
\text { patients }\end{array}$ \\
\hline Bococizumab (RN 316) & Pfizer [35] & $\begin{array}{l}2 \text { phase III trials with } 12,000 \\
\text { patients }\end{array}$ \\
\hline $\begin{array}{l}\text { ALN-PCSsc (ALN-PCSsc is a PCSK9 synthesis inhibitor } \\
\text { that works by degrading PCSK } 9 \text { mRNA inside the cell and } \\
\text { preventing the production of PCSK9 protein) }\end{array}$ & Alnylam pharmaceuticals [36] & Study design is in preparation \\
\hline \multicolumn{3}{|l|}{ Other PCSK9 modulators } \\
\hline Annexin 2 & Seidah et al. [37] & Animal experiments \\
\hline Berberin & Kong et al. [38] & Animal experiments \\
\hline Anti-sense RNA & Alnylam pharmaceuticals [36] & Phase I trials with 32 patients \\
\hline
\end{tabular}

independent of the applied statin doses [22]. The possible mechanisms explaining such behaviours are detailed by Zhang et al. [23]. They found that anti-PCSK9 antibody reduces LDL-C on top of a statin and suppresses hepatocyte SREBP-regulated genes. Other lipid-lowering sub- stances do not seem to have additional effects [22]. With respect to the given results, PCSK9 inhibition induced by anti-PCSK9 antibody may have a potential future in patients with heterozygous hypercholesterolemia and in patients suffering from statin myopathy, when the required 
Fig. 3. A potential treatment algorithm in relation to the use of PCSK9-AB and LA in treatment of patients with heterozygous hypercholesterolemia or mixed hypercholesterolemia (recommendation of authors). If the targets are achieved, therapy should be maintained and follow-up sessions should be carried out. PAD = Peripheral artery disease; CVD = cerebrovascular disease; $\mathrm{CHD}=$ coronary heart disease; PCSK9i = PCSK9-inhibitor; LA = lipoprotein apheresis.

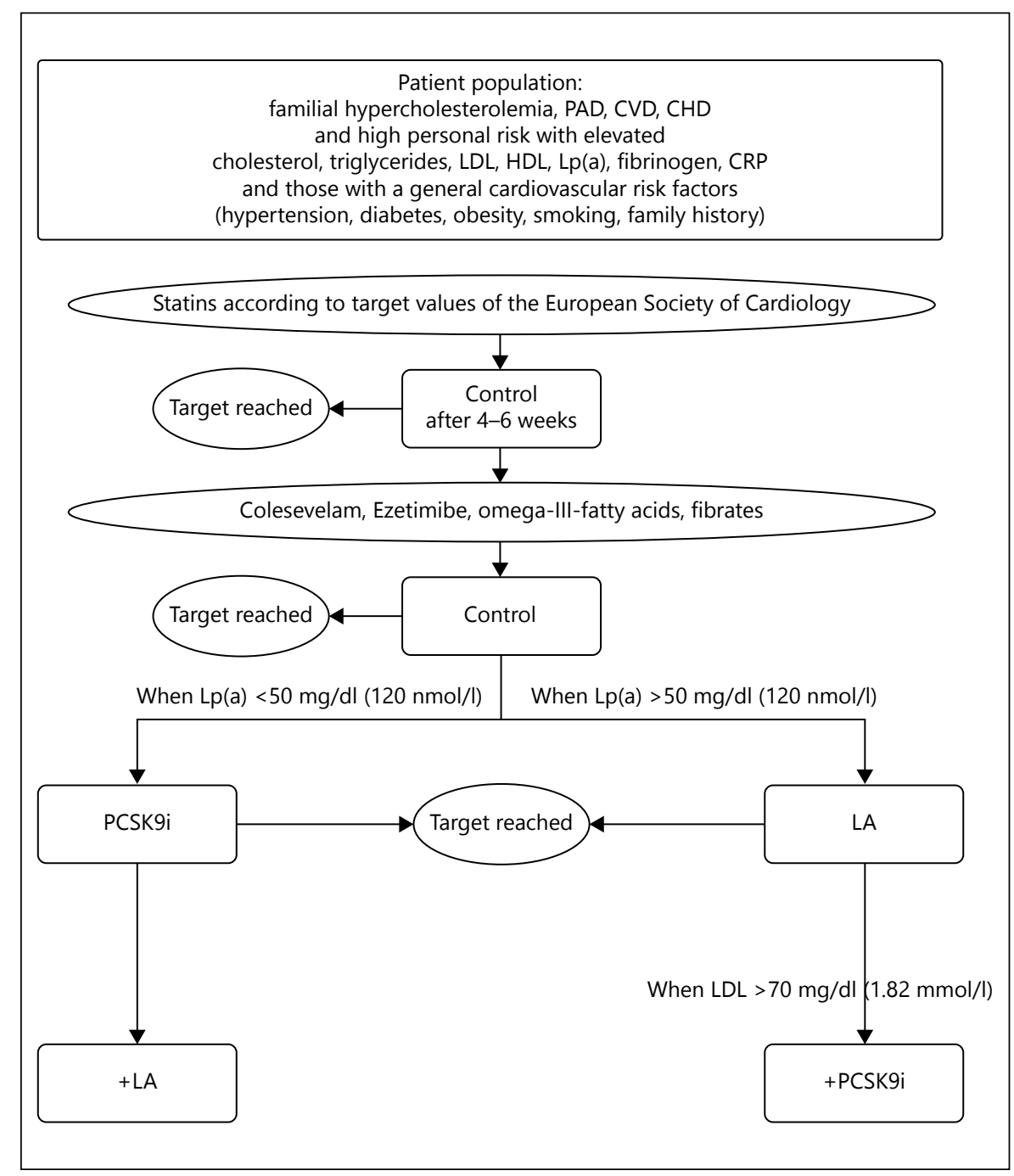

LDL-C goals could be reached, which in addition may correspond to cardiovascular event reduction [24]. Current studies also report a reduction in $\operatorname{Lp}(\mathrm{a})$-concentration by up to $32 \%$ [25]. For particularly high Lp(a)-concentrations, however, the relative reduction by PCSK9AB observed was only $16 \%$.

For both PCSK9-AB Evolocumab and Alirocumab, current studies show that in combination with statin medication, the required therapy goals for LDL-C levels of $<100 \mathrm{mg} / \mathrm{dl}(<2.6 \mathrm{mmol} / \mathrm{l})$ for patients at risk and $<70$ $\mathrm{mg} / \mathrm{dl}(<1.8 \mathrm{mmol} / \mathrm{l})$ for high-risk patients, respectively have been reached in more than $80-90 \%$ of cases $[22,26]$. How these very impressive results impact the rate of cardiovascular events is yet to be determined by ongoing studies (FOURIER respectively ODYSSEY OUTCOMES; US National Library of Medicine; ClinicalTrials.gov
2014; http://clinicaltrials.gov/ct2/show/NCT01764633, US National Library of Medicine; ClinicalTrials.gov 2014; http://clinicaltrials.gov/ct2/show/NCT01663402). On the other hand, the reduction of LDL-C with Evolocumab in homozygous $\mathrm{FH}$ was only $23 \%$ according to the TESLA-Part B trial [27].

For both PCSK9-AB good compatibility and little adverse effects of the substances, respectively have been found. Since the medication is administered subcutaneously every 14 days, main side effects are skin irritations (2-9\%). The problematic leukocytoclastic vasculitis that has already been reported in conjunction with other monoclonal antibody therapies did occur in a single case of PCSK9-AB therapy $[28,29]$. There is no significant difference between a 2 or 4 weeks administration because of an outcome of adverse effects [30]. 


\section{Conclusion and Outlook}

Results of current studies show, that in particular, a combination of PCSK9-AB and statins is independent of the dosage of the statins, suitable to increase the reduction of LDL-C by an additional $50-60 \%$. In contrast, the reduction of $L p(a)$-rates is, with a maximum of $32 \%$, significantly lower. Furthermore, it is remarkable that for high Lp(a)-concentrations, yet lower maximum reduction rates of up to $16 \%$ have been measured. In patients with the familial homozygous hypercholesterolemia, the PCSK9-AB therapy will remain an additional therapy to LA treatment. With this additional lipid-lowering therapy approach, the combination of statins, LA and PCSK9$\mathrm{AB}$, it could be possible to reduce LDL-C concentrations to target levels. Whether the approach is furthermore suited to inhibit cardiovascular progress in patients has to be determined by additional research. Should the analysis of ongoing PCSK9-AB studies show a reduction in the rate of cardiovascular events, the use of PCSK9-AB may present an alternative to LA for the treatment of patients with heterozygous hypercholesterolemia or mixed hypercholesterolemia (fig. 3). For patients with elevated Lp(a)- levels and related cardiovascular affections, the so far observed low reduction rates in $\operatorname{Lp}(\mathrm{a})$-concentrations suggest that PCSK9-AB is not an alternative treatment to LA (fig. 3). However, the antibody treatment may prove to be a valid add-on therapy. Despite the impressive LDL-C reduction rates, studies conducted so far have found only a few adverse effects. Whether the lipid reduction rates do impact the cardiovascular endpoint is yet to be determined by ongoing studies, such as, FOURIER or ODYSSEY OUTCOMES. Another crucial factor that determines the future range of application of this new and thus far very promising therapy approach will be the price of PCSK9-AB. Here, no information is available yet.

\section{Acknowledgements and Disclosure Statement}

C.L.N. and E.S. wish to confirm that there are no known conflicts of interest associated with this publication and there has been no significant financial support for this work that could have influenced its outcome.

V.J.J.S. has received honoraria for advisory boards and lectures from Amgen, Sanofi-Aventis, MSD, Fresenius Medical Care, B. Braun, Diamed.

\section{References}

1 Calling S, Ji J, Sundquist J, Sundquist K, Zoller B: Shared and non-shared familial susceptibility of coronary heart disease, ischemic stroke, peripheral artery disease and aortic disease. Int J Cardiol 2013;168:2844-2850.

2 Kavey RE, Allada V, Daniels SR, Hayman LL, McCrindle BW, Newburger JW, Parekh RS, Steinberger J: Cardiovascular risk reduction in high-risk pediatric patients: a scientific statement from the American Heart Association Expert Panel on Population and Prevention Science; the Councils on Cardiovascular Disease in the Young, Epidemiology and Prevention, Nutrition, Physical Activity and Metabolism, High Blood Pressure Research, Cardiovascular Nursing, and the Kidney in Heart disease; and the Interdisciplinary Working Group on Quality of Care and Outcomes Research: endorsed by the American Academy of Pediatrics. Circulation 2006;114:2710-2738.

3 Magnussen CG, Raitakari OT, Thomson R, Juonala M, Patel DA, Viikari JS, Marniemi J, Srinivasan SR, Berenson GS, Dwyer T, Venn A: Utility of currently recommended pediatric dyslipidemia classifications in predicting dyslipidemia in adulthood: evidence from the childhood determinants of adult health $(\mathrm{CDAH})$ study, Cardiovascular Risk in Young Finns Study, and Bogalusa Heart Study. Circulation 2008;117:32-42.
4 Ferdinand KC: Are cardiovascular benefits in statin lipid effects dependent on baseline lipid levels? Curr Atheroscler Rep 2011;13:64-72.

5 Taylor F, Huffman MD, Macedo AF, Moore TH, Burke M, Davey Smith G, Ward K, Ebrahim S: Statins for the primary prevention of cardiovascular disease. Cochrane Database Syst Rev 2013;1:CD004816.

6 Michos ED, Sibley CT, Baer JT, Blaha MJ, Blumenthal RS: Niacin and statin combination therapy for atherosclerosis regression and prevention of cardiovascular disease events: reconciling the aim-high (atherothrombosis intervention in metabolic syndrome with low HDL/high triglycerides: impact on global health outcomes) trial with previous surrogate endpoint trials. J Am Coll Cardiol 2012; 59:2058-2064.

7 Nordestgaard BG, Chapman MJ, Ray K, Boren J, Andreotti F, Watts GF, Ginsberg H, Amarenco P, Catapano A, Descamps OS, Fisher E, Kovanen PT, Kuivenhoven JA, Lesnik P, Masana L, Reiner Z, Taskinen MR, Tokgozoglu L, Tybjaerg-Hansen A: Lipoprotein(a) as a cardiovascular risk factor: current status. Eur Heart J 2010;31:28442853.

8 Jaeger BR, Richter Y, Nagel D, Heigl F, Vogt A, Roeseler E, Parhofer K, Ramlow W, Koch M, Utermann G, Labarrere CA, Seidel D:
Longitudinal cohort study on the effectiveness of lipid apheresis treatment to reduce high lipoprotein(a) levels and prevent major adverse coronary events. Nat Clin Pract Cardiovasc Med 2009;6:229-239.

9 Leebmann J, Roeseler E, Julius U, Heigl F, Spitthoever R, Heutling D, Breitenberger P, Maerz W, Lehmacher W, Heibges A, Klingel $\mathrm{R}$ : Lipoprotein apheresis in patients with maximally tolerated lipid-lowering therapy, lipoprotein(a)-hyperlipoproteinemia, and progressive cardiovascular disease: prospective observational multicenter study. Circulation 2013;128:2567-2576.

10 Neuvonen PJ: Drug interactions with HMGCoA reductase inhibitors (statins): the importance of CYP enzymes, transporters and pharmacogenetics. Curr Opin Investig Drugs 2010;11:323-332.

11 Catapano AL, Reiner Z, De Backer G, Graham I, Taskinen MR, Wiklund O, Agewall S, Alegria E, Chapman MJ, Durrington P, Erdine S, Halcox J, Hobbs R, Kjekshus J, Perrone Filardi P, Riccardi G, Storey RF, Wood D: ESC/EAS guidelines for the management of dyslipidaemias: the task force for the management of dyslipidaemias of the European Society of Cardiology (ESC) and the European Atherosclerosis Society (EAS). Atherosclerosis 2011;217(suppl 1):S1-S44. 
12 Cannon CP, Braunwald E, McCabe CH, Rader DJ, Rouleau JL, Belder R, Joyal SV, Hill KA, Pfeffer MA, Skene AM: Intensive versus moderate lipid lowering with statins after acute coronary syndromes. N Engl J Med 2004;350: 1495-1504.

13 Gitt AK, Junger C, Jannowitz C, Karmann B, Senges J, Bestehorn K: Adherence of hospitalbased cardiologists to lipid guidelines in patients at high risk for cardiovascular events (2l registry). Clin Res Cardiol 2011;100:277-287.

14 Visser ME, Wagener G, Baker BF, Geary RS, Donovan JM, Beuers UH, Nederveen AJ, Verheij J, Trip MD, Basart DC, Kastelein JJ, Stroes ES: Mipomersen, an apolipoprotein B synthesis inhibitor, lowers low-density lipoprotein cholesterol in high-risk statin-intolerant patients: a randomized, double-blind, placebo-controlled trial. Eur Heart J 2012;33:1142-1149.

15 Schettler V, Neumann CL, Hulpke-Wette M, Hagenah GC, Schulz EG, Wieland E: Current view: indications for extracorporeal lipid apheresis treatment. Clin Res Cardiol Suppl 2012;7:15-19.

16 Abifadel M, Varret M, Rabes JP, Allard D, Ouguerram K, Devillers M, Cruaud C, Benjannet S, Wickham L, Erlich D, Derre A, Villeger L, Farnier M, Beucler I, Bruckert E, Chambaz J, Chanu B, Lecerf JM, Luc G, Moulin P, Weissenbach J, Prat A, Krempf M, Junien C, Seidah NG, Boileau C: Mutations in PCSK9 cause autosomal dominant hypercholesterolemia. Nat Genet 2003;34:154-156.

17 Lambert G, Sjouke B, Choque B, Kastelein JJ, Hovingh GK: The PCSK9 decade. J Lipid Res 2012;53:2515-2524.

18 Cohen J, Pertsemlidis A, Kotowski IK, Graham R, Garcia CK, Hobbs HH: Low LDL cholesterol in individuals of African descent resulting from frequent nonsense mutations in PCSK9. Nat Genet 2005;37:161-165.

19 Cohen JC, Boerwinkle E, Mosley TH Jr, Hobbs HH: Sequence variations in PCSK9, low LDL, and protection against coronary heart disease. N Engl J Med 2006;354:1264-1272.

20 Dadu RT, Ballantyne CM: Lipid lowering with PCSK9 inhibitors. Nat Rev Cardiol 2014; 11:563-575.

21 Raal FJ, Stein EA, Dufour R, Turner T, Civeira F, Burgess L, Langslet G, Scott R, Olsson AG, Sullivan D, Hovingh GK, Cariou B, Gouni-Berthold I, Somaratne R, Bridges I, Scott R, Wasserman SM, Gaudet D: PCSK9 inhibition with evolocumab (AMG 145) in heterozygous familial hypercholesterolaemia (RUTHERFORD-2): a randomised, double-blind, placebo-controlled trial. Lancet 2014;385:331-340.

22 Blom DJ, Hala T, Bolognese M, Lillestol MJ, Toth PD, Burgess L, Ceska R, Roth E, Koren MJ, Ballantyne CM, Monsalvo ML, Tsirtsonis K, Kim JB, Scott R, Wasserman SM, Stein EA: A 52-week placebo-controlled trial of evolocumab in hyperlipidemia. N Engl J Med 2014;370:1809-1819.
23 Zhang L, McCabe T, Condra JH, Ni YG, Peterson LB, Wang W, Strack AM, Wang F, Pandit S, Hammond H, Wood D, Lewis D, Rosa R, Mendoza V, Cumiskey AM, Johns DG, Hansen BC, Shen X, Geoghagen N, Jensen $\mathrm{K}$, Zhu L, Wietecha K, Wisniewski D, Huang L, Zhao JZ, Ernst R, Hampton R, Haytko P, Ansbro F, Chilewski S, Chin J, Mitnaul LJ, Pellacani A, Sparrow CP, An Z, Strohl W, Hubbard B, Plump AS, Blom D, Sitlani A: An anti-PCSK9 antibody reduces LDL-cholesterol on top of a statin and suppresses hepatocyte SREBP-regulated genes. Int J Biol Sci 2012;8: 310-327.

24 Romagnuolo R, Scipione CA, Boffa MB, Marcovina SM, Seidah NG, Koschinsky ML: Lipoprotein(a) catabolism is regulated by proprotein convertase subtilisin/kexin type 9 through the low density lipoprotein receptor. J Biol Chem 2015;290:11649-11662.

25 Desai NR, Kohli P, Giugliano RP, O’Donoghue ML, Somaratne R, Zhou J, Hoffman EB, Huang F, Rogers WJ, Wasserman SM, Scott R, Sabatine MS: AMG145, a monoclonal antibody against proprotein convertase subtilisin kexin type 9, significantly reduces lipoprotein(a) in hypercholesterolemic patients receiving statin therapy: an analysis from the LDL-c assessment with proprotein convertase subtilisin kexin type 9 monoclonal antibody inhibition combined with statin therapy (LAPLACE)-thrombolysis in myocardial infarction (TIMI) 57 trial. Circulation 2013;128:962-969.

26 Robinson JG, Nedergaard BS, Rogers WJ, Fialkow J, Neutel JM, Ramstad D, Somaratne R, Legg JC, Nelson P, Scott R, Wasserman SM, Weiss R: Effect of evolocumab or ezetimibe added to moderate- or high-intensity statin therapy on LDL-C lowering in patients with hypercholesterolemia: the LAPLACE-2 randomized clinical trial. JAMA 2014;311:18701882 .

27 Margaritis M, Antoniades C: Statins in coronary artery bypass grafting surgery: lipid lowering and beyond. Expert Rev Cardiovasc Ther 2012;10:5-8.

28 McKenney JM, Koren MJ, Kereiakes DJ, Hanotin C, Ferrand AC, Stein EA: Safety and efficacy of a monoclonal antibody to proprotein convertase subtilisin/kexin type 9 serine protease, SAR236553/REGN727, in patients with primary hypercholesterolemia receiving ongoing stable atorvastatin therapy. J Am Coll Cardiol 2012;59:2344-2353.

29 Raal F, Scott R, Somaratne R, Bridges I, Li G, Wasserman SM, Stein EA: Low-density lipoprotein cholesterol-lowering effects of AMG 145 , a monoclonal antibody to proprotein convertase subtilisin/kexin type 9 serine protease in patients with heterozygous familial hypercholesterolemia: the reduction of LDL$\mathrm{C}$ with PCSK9 inhibition in heterozygous familial hypercholesterolemia disorder (RUTHERFORD) randomized trial. Circulation 2012;126:2408-2417.
30 Stein EA, Honarpour N, Wasserman SM, Xu F, Scott R, Raal FJ: Effect of the proprotein convertase subtilisin/kexin 9 monoclonal antibody, AMG 145, in homozygous familial hypercholesterolemia. Circulation 2013;128: 2113-2120.

31 Roth EM, McKenney JM: ODYSSEY MONO: effect of alirocumab $75 \mathrm{mg}$ subcutaneously every 2 weeks as monotherapy versus ezetimibe over 24 weeks. Future Cardiol 2015;11: 27-37.

32 Langslet G, Emery M, Wasserman SM: Evolocumab (AMG 145) for primary hypercholesterolemia. Expert Rev Cardiovasc Ther 2015;13:477-488.

33 Raal FJ, Honarpour N, Blom DJ, Hovingh GK, Xu F, Scott R, Wasserman SM, Stein EA: Inhibition of PCSK9 with evolocumab in homozygous familial hypercholesterolaemia (TESLA Part B): a randomised, double-blind, placebo-controlled trial. Lancet 2015;385: 341-350.

34 Raal FJ, Stein EA, Dufour R, Turner T, Civeira F, Burgess L, Langslet G, Scott R, Olsson AG, Sullivan D, Hovingh GK, Cariou B, Gouni-Berthold I, Somaratne R, Bridges I, Scott R, Wasserman SM, Gaudet D: PCSK9 inhibition with evolocumab (AMG 145) in heterozygous familial hypercholesterolaemia (RUTHERFORD-2): a randomised, doubleblind, placebo-controlled trial. Lancet 2015; 385:331-340.

35 Ballantyne CM, Neutel J, Cropp A, Duggan W, Wang EQ, Plowchalk D, Sweeney K, Kaila $\mathrm{N}$, Vincent J, Bays H: Results of bococizumab, a monoclonal antibody against proprotein convertase subtilisin/kexin type 9 , from a randomized, placebo-controlled, dose-ranging study in statin-treated subjects with hypercholesterolemia. Am J Cardiol 2015;115: 1212-1221.

36 Fitzgerald K, Frank-Kamenetsky M, ShulgaMorskaya S, Liebow A, Bettencourt BR, Sutherland JE, Hutabarat RM, Clausen VA, Karsten V, Cehelsky J, Nochur SV, Kotelianski V, Horton J, Mant T, Chiesa J, Ritter J, Munisamy M, Vaishnaw AK, Gollob JA, Simon A: Effect of an RNA interference drug on the synthesis of proprotein convertase subtilisin/ kexin type 9 (PCSK9) and the concentration of serum LDL cholesterol in healthy volunteers: a randomised, single-blind, placebocontrolled, phase 1 trial. Lancet 2014;383:6068.

37 Seidah NG, Poirier S, Denis M, Parker R, Miao B, Mapelli C, Prat A, Wassef H, Davignon J, Hajjar KA, Mayer G: Annexin A2 is a natural extrahepatic inhibitor of the PCSK9induced LDL receptor degradation. PLoS One 2012;7:e41865.

38 Kong A, Li X, Ni Z, Wang Y: [Simultaneous determination of berberin hydrochloride, baicalin and glibenclamide in kangtang tablets by RP-HPLC]. Se Pu 2004;22:89. 